\title{
ÇALIŞMA DURUŞLARININ BULANIK ORTAMDA ANALIZi VE ERGONOMİK İŞ İSTASYONU TASARIM ÖNERİLERİ
}

\author{
Gülin Feryal CAN ${ }^{1}$, Kumru Didem ATALAY ${ }^{1}$, Ergün ERASLAN ${ }^{2}$ \\ ${ }^{1}$ Başkent Üniversitesi, Mühendislik Fakültesi, Endüstri Mühendisliği Bölümü, Etimesgut, 06810, Ankara \\ ${ }^{2}$ Yıldırım Beyazıt Üniversitesi, Mühendislik ve Doğa Bilimleri Fakültesi, Endüstri Müh., Bölümü, Ulus, Ankara \\ gfcan@baskent.edu.tr, katalay@baskent.edu.tr, eraslan@ybu.edu.tr
}

(Geliş/Received: 03.09.2014; Kabul/Accepted: 27.07.2015)

\section{ÖZET}

İş ortamlarında ergonomik tasarım uygulamalarının gerçekleştirilmesi ile çalışanların sağlı̆̆ını korumak, iş konforu sağlamak ve üretim verimliliğini artırmak mümkün olmaktadır. Bu nedenle, işletmelerde çalışanlara yönelik ergonomik iş istasyonu tasarımları oldukça önemli bir yere sahiptir. $\mathrm{Bu}$ çalışmada, metal aksesuar üretimi yapan bir firmada, ergonomik koşulların analizi sonucu tasarım açısından uygun olmayan iş istasyonları incelenmiştir. Uygunsuz tasarımlar, çalışanların tehlikeli duruşları tekrarlı bir şekilde sergilemelerine yol açmaktadır. Bunun sonucunda, üretim süreci yavaşlamakta ve çalışanlarda artan bir yorgunluk hissi oluşmaktadır. Çalışanların duruşları, Klasik Hızlı Tüm Vücut Değerlendirme Yöntemine (Rapid Entire Body Assessment-REBA) üçgensel bulanık skala eklenmesiyle geliştirilen Bulanık REBA (BREBA) yöntemi ile analiz edilmiştir. BREBA Yöntemi, duruşların tüm vücutta yarattığı tehlike seviyesini belirlerken ortaya çıkabilecek bilgi kayıplarını da önlemekte ve bulanık ortamda daha doğru sonuçlar elde edilmesini sağlamaktadır. İşletmede, dört iş istasyonuna ait (1sıl işlem, birinci pres, ikinci pres ve taşıma istasyonu) 688 adet duruş fotoğrafi değerlendirilmiştir. Değerlendirme sonucunda, ısıl işlem istasyonunda bacak, üst kol ve bilek; pres istasyonlarında bacak, bilek ve gövde; taşıma istasyonunda ise gövde ve üst kol bölümlerinin en çok zorlanan bölümler olduğu ortaya çıkmıştır. İmalat sürecinde sergilenen duruşların \% 52,03'ünün orta düzeyde risk içerdiği belirlenmiş ve iyileştirme öneriler sunulmuştur.

Anahtar Kelimeler: Çalışma duruşu, ergonomik tasarım, bulanık mantık, bulanık REBA

\section{WORKING POSTURE ANALYSIS IN FUZZY ENVIRONMENT AND ERGONOMIC WORK STATION DESIGN RECOMMENDATIONS}

\begin{abstract}
Realization of ergonomic design applications in working environments, makes it possible to preserve the health of employees, provide them working comfort and increase productivity. Therefore ergonomic work station design has an outstanding position in work places. In this study, an investigation was made on work stations in a metal accessor producer, which were found to be inappropriate from point of view of design considerations as a result of an ergonomic condition analysis. Inappropriate designs force workers to repetitively assume dangerous postures. As a result production process slows down and workers experience a feeling of increasing tiredness. Postures of workers were analyzed by The Fuzzy Rapid Entire Body Assessment (BREBA) developed by inserting triangular fuzzy scale to Rapid Entire Body Assessment (REBA). The BREBA method determines the level of risk in whole body caused by postures while prevents potential information loss and allows obtaining more accurate results in a fuzzy environment. In the said working place, 688 posture photographs belonging to four work stations (heat treatment, primary press, secondary press and transportation station) were examined. The consequent assessment suggested that; leg, upper arm and wrist in heat treatment, leg, wrist and torso in pres station, torso and arm were found to be the most enforced body sections. The results pointed out that $52,03 \%$ of postures displayed in production process introduced medium level risk and improvements were suggested.
\end{abstract}

Keywords: Working posture, ergonomic design, fuzzy logic, fuzzy REBA 


\section{GIRIŞ̧ (INTRODUCTION)}

Rekabet ortamında işletmelerin hammadde, enerji, işgücü, sermaye gibi üretim girdilerini etkin bir şekilde yönetmeleri ve doğru yönlendirmeleri gerekir. $\mathrm{Bu}$ girdiler arasında işgücünün de (çalışanlar) önemli bir yere sahip olduğu açıktır. İşletmeler tarafindan çalışanlara yönelik yapılacak iş düzenlemeleri üretim verimliliğini doğrudan etkiler. $\mathrm{Bu}$ düzenlemeler kapsamında çalışana uyumlu iş istasyonu tasarımı, performansı olumlu yönde değiştirir [1].

Ergonomik tasarım prensiplerinin uygulandığ istasyonlarda çalışanlar, yüksek konfora ve iş tatminine sahip olurlar. $\mathrm{Bu}$ tür istasyonlar çalışana rahat hareket imkânı verir, parçalara, alet-teçhizata ulaşmayı kolaylaştırır ve fiziksel zorlanmayı azaltır. Diğer istasyonlar ve taşıma sistemleriyle uyumlu bir iş akışı sağlar. Ayrıca çalışanlar, farklı açı ve yükseklikler için kolaylıkla kendilerine uygun düzenlemeler yapabilirler [2].

İş istasyonu tasarımı çalışma duruşunu da önemli ölçüde etkiler. En genel tanımıyla çalışma duruşu, vücudun baş, gövde, kol ve bacak üyelerinin yapılan işe ve iş istasyonu tasarımına göre şekillenmesidir [3]. $\mathrm{Bu}$ tasarım, çalışanların uzanma, tutma ve ekipman kullanma gibi yeteneklerini, aynı zamanda yorgunluk ve kas-iskelet sistemi sorunları yaşamadan işlerini ne kadar süre yapabileceklerini belirler. Uygun olmayan tasarımlar ise performansı düşürür ve üretim sürecini yavaşlatır.

Literatürde farklı yöntemler kullanarak çalışma duruşlarını analiz eden ve elde edilen sonuçları iş istasyonu tasarımına aktaran çalışmalara sıklıkla rastlanmaktadır. Buchholz vd. (1996) yol yapım işinde çalışanların duruşlarını PATH (PostureActivities-Tools and Handling) ile analiz etmişler ve tehlikeli duruşları azaltmak için önerilerde bulunmuşlardır [4]. Higgnett ve McAtamney (1999) tarafindan ergonomistler, fizyoterapistler, ve hemşirelerden oluşan grupların çalışma duruşları incelenmiş ve 600' den fazla duruş örneğine REBA yöntemi uygulanarak tehlike seviyeleri belirlenmiştir [5]. Akay vd. (2003), bir oto-servis istasyonunda sergilenen çalışma duruşlarına OWAS yöntemini uygulamışlar ve duruşlara ilişkin iyileştirme önerileri geliştirmişlerdir [3]. Choobineh vd. (2004) tarafindan bir halı dokuma atölyesindeki iş istasyonu tasarımı revize edilmiştir. Bunun için dokuma sürecine ilişkin bilgiler NMQ (Nordic Musculoskeletal Questionaire) ile toplanmıştır. Mevcut ve iyileştirilen istasyonda sergilenen çalışma duruşları ise RULA (Rapid Upper Limb Assessment) ile analiz edilmiştir [6]. Shuval ve Donchin (2005), monitör takip çalışanlarında üst ekstremitede oluşan kas-iskelet semptomlarının nedenlerini araştırmışlardır. Çalışma duruşlarının analizinde RULA Yöntemini kullanmışlardır [7].
Diniz de SA vd. (2006) tarafından, diş hekimliği öğrencilerinin çalışma duruşları RULA ve REBA (Rapid Entire Body Assessment) yöntemleri kullanılarak analiz edilmiş ve sonuçlar karşılaştırılmıştır [8]. Jones ve Kumar (2007), testere mili üreten bir fabrikada çalışanların duruşlarını REBA, ACGIH TLV (American Conference of Industirial Hygenist Treshold Limit Values), İşte Zorlanma İndeksi (Job Strain Index) ve OCRA (The Occupational Repetitive Actions) yöntemlerini kullanarak analiz etmiş ve sonuçları karşılaştırmışlardır [9]. Battini vd. (2010), REBA yöntemini uygulayarak bir montaj sisteminde sergilenen çalışma duruşlarını incelemiş ve sonuçlara göre sistemin yeniden tasarımını yapmışlardır [10]. Kaufman ve Ratzon (2011), profesyonel klasik müzik sanatçılarının çalışma duruşlarını RULA ile analiz etmişlerdir [11]. Dockrell vd. (2012) çalışmalarında, RULA yöntemini kullanarak ilköğretim öğrencilerinin sınıfta sergiledikleri duruşları değerlendirmişlerdir. Analiz sonuçlarına göre sınıfta yapılacak tasarım değişikliklerini belirlemişlerdir [12]. Liu vd. (2012) tarafindan mobil onarım barınaklarının ergonomik analizi Bulanık AHP metodu kullanılarak yapılmıştır [13]. Abargohei vd. (2012), bir eğitim merkezinde bulanık vücut haritalama yöntemini kullanarak makro ve mikro ergonomik iyileştirme çalışmalarını gerçekleştirmişlerdir [14]. Zhou vd. (2013), oturarak yapılan onarım işlerinde sergilenen çalışma duruşlarını bir kayıt cihazı ile zamanı ve iş yükünü temel alarak analiz etmişlerdir [15]. Isa vd. (2014), CNC freze makinası kullanan operatörlerin çalışma duruşlarını RULA ile analiz etmişler ve elde edilen sonuçları makinenin yeniden tasarımında kullanmışlardır [16]. Atalay ve Eraslan (2014), MP3 çalarların kullanılabilirliğini Bulanık TOPSIS (Fuzzy Technique for Order Preference by Similarity to Ideal Solution-FTOPSIS), Bulanık Analitik Hiyerarşi Prosesi (Fuzzy Analytic Hierarchy Process-FAHP), Bulanık Aksiyomatik Tasarım Teorisi (Fuuzy Axiomatic Design Theory-FADT) yöntemlerini kullanarak değerlendirmiş ve sonuçları karşılaştırmışlardır [17].

Bu çalışmada, elektrik trafoları için metal aksesuar üreten bir firmada, pim imalatının yapıldı̆̆ 1 iş istasyonlarında sergilenen duruşlar Bulanık REBA (BREBA) Yöntemi ile analiz edilmiştir. Analiz sonucunda, bu duruşlara ilişkin elde edilen tehlike seviyelerine göre istasyon tasarımları için iyileştirme önerileri sunulmuştur. Çalışma duruşlarının analizinde, geliştirilen BREBA Yönteminin kullanılması ile Klasik REBA yöntemindeki açısal duruş değerlendirmelerinin daha sağlıklı ve esnek bir şekilde yapılması sağlanmaktadır. Klasik REBA yöntemi tüm vücudu gözleme dayalı bir şekilde analiz etmekte ve bu durum sonuçlarda sapmalara yol açmaktadır. Herhangi bir vücut bölümünün açısal duruşunun gözlem yolu ile net bir şekilde belirlenmesi 
mümkün değildir. Bu değer, ancak yaklaşık olarak veya bir aralık içerisinde belirlenebilir. $\mathrm{Bu}$ nedenle üçgensel bulanık skala kullanılarak bir algoritma geliştirilmiştir. Duruş analizinde, BREBA Yöntemini kullanan ve sonuçları bulanık mantığın esnekliğiyle ortaya koyan başka bir çalışmaya literatürde rastlanmamıştır. Geliştirilen bu yöntem aşağıda verilmektedir.

\section{BREBA YÖNTEMİ (FREBA METHOD)}

Klasik REBA ile çalışma duruşlarının analizi hem nitel hem nicel değişkenlerin birlikte yer aldığı bir süreçtir. Burada açısal duruş analizleri nicel, opsiyonel (yana eğilme, dönme, bükülme vb.) duruş analizleri ise nitel değişkenlerden oluşur. Bununla birlikte duruşların açısal değişimleri, birbirinden bağımsız olarak, yapılan işe, çalışanın vücut yapısına ve iş istasyonu tasarımına göre değişen eylemlerdir. $\mathrm{Bu}$ değerlendirmeler, Klasik REBA'da yaklaşık olarak yapılır ve insan gözünün algısına göre değişkenlik gösterir. Buna göre bulanık mantığın çalışma duruşlarının analizinde kullanılması bir çok avantaj sağlar. Bulanık mantık, belirsizlik durumlarında daha doğru sonuçlar veren bir araçtır [17]. Ayrıca nitel ve nicel değişkenlerin birlikte kullanıldığı değerlendirmeler için uygundur [18].

\subsection{Bulanık Mantık, Bulanık Kümeler ve Bulanık Aritmetik (Fuzzy Logic, Fuzzy Sets and Fuzzy Arithmetic)}

Zadeh $1965^{\prime}$ de olasılık teorisine alternatif olarak bulanık mantığı geliştirmiştir. Belirsizliği ölçmek için ortaya attığı bulanık küme teorisi sürekli değerli mantığı temel alır ve ikili mantık sistemine göre daha esnektir. [19].

Bulanık mantık, yüksek karmaşıklığa sahip, davranışları tam anlamıyla belirlenemeyen sistemleri içeren ve yaklaşık değerlendirmelerle hızlı çözüm gerektiren durumlarda kullanılmaya elverişlidir [21].

Zadeh, [0,1] sürekli kapalı aralığında tanımlanan farklı üyelik derecelerini temsil etmek için üyelik fonksiyonunu geliştirmiştir. $\mathrm{Bu}$ fonksiyon, kümeye ait olma derecelerini gösteren matematiksel bir kavramdır. Üyelik fonksiyonunun matematiksel gösterimi

$\mu_{\tilde{A}}(x) \in[0,1]$

ile verilir. Burada, $\sim$ bulanıklığı temsil eder ve $\mu_{\tilde{A}}(x)$ sembolü, $\tilde{A}$ bulanık kümesinin elemanı olan $x$ 'in üyelik derecesini gösterir [19].

Tanım 1. Üçgensel Bulanık Sayı (ÜBS) $\tilde{A},(l, m, u)$ notasyonu ile gösterilir. Burada $(l, m, u)$ gerçel sayılar olmak üzere $m$ merkez, $l$ ve $u$ sirasiyla sağ ve sol yayılımları temsil etmektedir ve $l \leq m \leq u$ 'dur. $\tilde{A}$ kümesine ait üçgensel üyelik fonksiyonu $\mu_{\tilde{A}}(x)$
$\mu_{\tilde{A}}(x)=\left\{\begin{array}{cl}0, & x<l, x>u \\ \frac{(x-l)}{(m-l)}, & l \leq x \leq m \\ \frac{(u-x)}{(u-m)} & m \leq x \leq u\end{array}\right.$

biçiminde tanımlanır.

$\tilde{A}_{1}=\left(l_{1}, m_{1}, u_{1}\right)$ ve $\tilde{A}_{2}=\left(l_{2}, m_{2}, u_{2}\right)$ iki ÜBS olmak üzere bulanık aritmetik operasyonlar aşağıdaki gibi verilir:

$\tilde{A}_{1} \oplus \tilde{A}_{2}=\left(l_{1}+l_{2}, m_{1}+m_{2}, u_{1}+u_{2}\right)$

$\tilde{A}_{1}-\tilde{A}_{2}=\left(l_{1}-l_{2}, m_{1}-m_{2}, u_{1}-u_{2}\right)$

$\tilde{A}_{1} \otimes \tilde{A}_{2}=\left(l_{1} * l_{2}, m_{1} * m_{2}, u_{1} * u_{2}\right)$

$\tilde{A}_{1} \odot \tilde{A}_{2}=\left(l_{1} / u_{2}, m_{1} / m_{2}, u_{1} / l_{2}\right)$

$\lambda * \tilde{A}=(\lambda * l, \lambda * m, \lambda * u)$

\subsection{BREBA Algoritması (FREBA Algorithm)}

Klasik REBA yöntemi, kontrol listesi kullanılarak uygulanan gözleme dayalı bir yöntemdir. Yöntem sonucunda elde edilen REBA Final Skoru ile bir iş istasyonunda sergilenen çalışma duruşlarının tehlike seviyesi tüm vücut için belirlenir [5]. Bu tehlike seviyesine göre, istasyonda iyileştirmelerin yapılıp yapılmayacağına karar verilir. REBA yöntemi ile analiz yapılırken kullanıcı vücudun sağ veya sol yanından birini ya da her ikisini gözlemleyebilir. Hangi duruşların analiz edileceği kararı ise en uzun zaman alan, en sık tekrar eden ya da en tehlikeli olduğu düşünülen duruş ya da duruşların belirlenmesiyle verilir. REBA vücudu $A$ ve $B$ grubuna ayırarak inceler. A grubunda gövde, boyun ve bacak bölümleri, B grubunda ise üst kol, alt kol, bilek bölümleri yer alır. A Grubu 60 farklı, B Grubu 36 farklı duruş kombinasyonu içerir.

Çalışmada geliştirilen BREBA Yönteminde ise Klasik REBA Yönteminin karar kuralları değiştirilmeden, kesin değerler yerine bulanık sayılar kullanılmıştır. Buna göre BREBA Yönteminde, her iki grupta yer alan vücut bölümlerinin açısal hareketlerinin değerlendirilmesinde ve Tablolarda (Tablo A, B, C ve Final REBA Skoru Tablosu) verilen skorlamalarda ÜBS'larla işlemler yapılmıştır. Bu skorlar “ “" " ile " ‘Тै" arasında değişen ÜBS'lardan oluşmaktadır. Bulanık skorun değeri arttıkça duruşun risk seviyesi artar. Çalışmada kullanılan Bulanık Skorlar (BS) ve bunlara ilişkin ÜBS'larının değerleri Tablo 1 ile verilmiştir.

Tablo 1'de verilen BS'lar kullanılarak geliştirilen BREBA Yöntemine ilişkin algoritma 14 adımdan oluşur. Bu adımlar sırasıyla aşağıda yer almaktadır:

Adım 1: Bu adım boyun bölümüne ait üç farklı açısal duruşun ve iki farklı opsiyonel hareketin değerlendirilmesinden oluşur. 
Tablo 1. Bulanık Skorlar (BS) (Fuzzy Scores (FS))

\begin{tabular}{|c|c|c|c|c|c|c|c|c|c|c|c|c|}
\hline BS & $\tilde{1}$ & $\tilde{2}$ & $\tilde{3}$ & $\tilde{4}$ & $\tilde{5}$ & $\tilde{6}$ & $\tilde{7}$ & $\tilde{8}$ & $\tilde{9}$ & $\widetilde{10}$ & $\widetilde{11}$ & $\widetilde{12}$ \\
\hline ÜBS & $(1,1,2)$ & $(1,2,3)$ & $(2,3,4)$ & $(3,4,5)$ & $(4,5,6)$ & $(5,6,7)$ & $(6,7,8)$ & $(7,8,9)$ & $(8,9,10)$ & $(9,10,11)$ & $(10,11,12)$ & $(11,12,12)$ \\
\hline
\end{tabular}

Tablo 2. Bulanık Tablo A (Fuzzy Table A)

\begin{tabular}{|c|c|c|c|c|c|c|c|c|c|c|c|c|c|}
\hline \multirow{2}{*}{ Bulanık Tablo A } & \multicolumn{13}{|c|}{ BBOS } \\
\hline & & \multicolumn{4}{|c|}{$\tilde{1}$} & \multicolumn{4}{|c|}{$\tilde{2}$} & \multicolumn{4}{|c|}{$\tilde{3}$} \\
\hline & BBAS & $\tilde{1}$ & $\tilde{2}$ & $\tilde{3}$ & $\tilde{4}$ & $\tilde{1}$ & $\tilde{2}$ & $\tilde{3}$ & $\tilde{4}$ & $\tilde{1}$ & $\tilde{2}$ & $\tilde{3}$ & $\tilde{4}$ \\
\hline \multirow{5}{*}{ BGS } & $\tilde{1}$ & $\tilde{1}$ & $\tilde{2}$ & $\tilde{3}$ & $\tilde{4}$ & $\tilde{1}$ & $\tilde{2}$ & $\widetilde{3}$ & $\tilde{4}$ & $\tilde{3}$ & $\tilde{3}$ & $\tilde{5}$ & $\tilde{6}$ \\
\hline & $\tilde{2}$ & $\tilde{2}$ & $\tilde{3}$ & $\tilde{4}$ & $\tilde{5}$ & $\tilde{3}$ & $\tilde{4}$ & $\tilde{5}$ & $\tilde{6}$ & $\tilde{4}$ & $\tilde{5}$ & $\tilde{6}$ & $\tilde{7}$ \\
\hline & $\widetilde{3}$ & $\tilde{2}$ & $\tilde{4}$ & $\tilde{5}$ & $\tilde{6}$ & $\tilde{4}$ & $\tilde{5}$ & $\tilde{6}$ & $\tilde{7}$ & $\tilde{5}$ & $\tilde{6}$ & $\tilde{7}$ & $\tilde{8}$ \\
\hline & $\tilde{4}$ & $\widetilde{3}$ & $\tilde{5}$ & $\tilde{6}$ & $\tilde{7}$ & $\tilde{5}$ & $\tilde{6}$ & $\tilde{7}$ & $\widetilde{8}$ & $\tilde{6}$ & $\tilde{7}$ & $\widetilde{8}$ & $\widetilde{9}$ \\
\hline & $\tilde{5}$ & $\tilde{4}$ & $\tilde{6}$ & $\tilde{7}$ & $\widetilde{8}$ & $\tilde{6}$ & 7 & $\widetilde{8}$ & $\widetilde{q}$ & $\tilde{7}$ & $\widetilde{8}$ & $\widetilde{9}$ & $\widetilde{9}$ \\
\hline
\end{tabular}

Açısal değerlendirmelere ait skorlar ÜBS ile verilmiştir. Buna göre boyun, fileksiyon (öne eğilme) hareketini $0^{\circ}-20^{\circ}$ arasinda yapıyor ise $(1,1,2), 20^{\circ}$ 'den fazla yapıyor ise $(1,2,3)$ ve ekstansiyon (geriye eğilme) hareketi yapıyor ise $(1,2,3)$ ÜBS'ları kullanılır. İki farklı opsiyonel hareket ise (dönme $(+1)$, yana eğilme $(+1))$ net bir şekilde belirlenebildiği için bu hareketlere ait puanlara kesin değerler atanmıştır. Bu değerler ÜBS'lara eklenerek Bulanık Boyun Skoru (BBOS) elde edilir.

Adım 2: Bu adım gövde bölümüne ait beş farklı açısal duruşun ve iki farklı opsiyonel hareketin değerlendirilmesinden oluşur. Gövde, nötral pozisyonda $\left(0^{\circ}\right)$ ise $(1,1,2)$, fileksiyon hareketini $0^{\circ}-20^{\circ}$ arasında yapiyor ise $(1,2,3), 20^{\circ}-60^{\circ}$ arasinda yapiyor ise $(2,3,4), 60^{\circ}$ 'den fazla yapıyor ise $(3,4,5)$ ve ektansiyon hareketi yapıyor ise $(1,2,3)$ ÜBS'ları kullanılır. İki farklı opsiyonel hareket ise (dönme $(+1)$, yana eğilme $(+1)$ ) net bir şekilde belirlenebildiği için bu hareketlere ait puanlara kesin değerler atanmıştır. Bu değerler, ÜBS'lara eklenerek Bulanık Gövde Skoru (BGS) elde edilir.

Adım 3: $\mathrm{Bu}$ adım bacak bölümüne ait iki farklı duruşun ve iki farklı açısal opsiyonel hareketin değerlendirilmesinden oluşur. Burada açısal opsiyonel değerlendirmelere ait puanlar ÜBS'lar ile verilmiştir. Bacağa ait duruşlara ise (tek $(+1)$ veya her iki ayağın yere basması $(+2)$ ) kesin değerler atanmıştır. Buna göre bacak fileksiyon hareketini $30^{\circ}-60^{\circ}$ arasında yapıyor ise kesin değere $(1,1,2), 60^{\circ}$ 'den fazla yapıyor ise $(1,2,3)$ ÜBS'sı eklenir ve Bulanık Bacak Skoru (BBAS) elde edilir.

Adım 4: İlk üç adımda hesaplanan skorlar Tablo 2 ile verilen Bulanık Tablo A'da kesiştirilerek A Grubuna ait BS hesaplanır. Buna göre öncelikle BBOS, sonra BBAS'na bakılır ve BGS ile BBAS kesiştirilerek A Grubuna ait BS elde edilir.
Adım 5: Bu adım üç farklı yük-kuvvet koşulunun ve bir adet opsiyonel koşulun değerlendirilmesinden oluşur. Yük-kuvvet koşullarına ilişkin skorlamalar kesin değerler ile opsiyonel koşula ilişkin skorlamalar da ÜBS ile verilmiştir. Çünkü yük-kuvvet koşulları birlikte çalışılan ağırlığa göre değişir ve net olarak ölçülebilir. Opsiyonel koşul ise yapılan işin ani ve hızlı bir şekilde kuvvet uygulanmasını gerektirip gerektirmediğini belirler. Bu nedenle gözlemciye göre değişkenlik gösterir. Eğer yapılan iş böyle bir hareketi gerektiriyorsa $(1,1,2)$ ÜBS'sı atanır ve bu sayı kesin değerlere eklenerek Bulanık Yük-Kuvvet Skoru (BYKS) elde edilir.

Adım 6: BYKS Bulanık Tablo A Skoruna eklenerek Bulanık A Skoru (BAS) elde edilir.

Adım 7: Bu adım üst kol bölümüne ait beş farklı açısal duruşun ve üç farklı opsiyonel hareketin değerlendirilmesinden oluşur. Üst kol, nötral pozisyonda ise $\left(0^{\circ}-20^{\circ}\right.$ fileksiyon ya da ekstansiyon hareketi yapıyorsa) $(1,1,2)$, fileksiyon hareketini $20^{\circ}$ $45^{\circ}$ arasinda yapiyor ise $(1,2,3), 45^{\circ}-90^{\circ}$ aras yapiyor ise $(2,3,4), 90^{\circ}$ 'den fazla yapiyor ise $(3,4,5)$ ve ekstansiyon hareketi yapıyor ise $(1,2,3)$ ÜBS'sı alınır. Üç farklı opsiyonel hareket (omuzlar yukarı kalkmışsa $(+1)$, üst kol yana açılmışsa $(+1)$, kol desteklenmişse veya çalışan yaslanarak iş yapıyorsa (1)) ise net bir şekilde belirlenebildiği için bu hareketlere ait puanlar kesin değer olarak atanmıştır. $\mathrm{Bu}$ değerler ÜBS'lara eklenerek Bulanık Üst Kol Skoru (BÜKS) elde edilir.

Adım 8: Bu adım üç farklı açısal alt kol duruşunun değerlendirilmesinden oluşur. Alt kol fileksiyon hareketini $60^{\circ}-100^{\circ}$ arasında yapıyor ise Bulanık Alt Kol Skoru (BAKS) $(1,1,2), 100^{\circ}$ 'den fazla yapıyor ise BAKS $(1,2,3)$ ve $0^{\circ}-60^{\circ}$ aras 1 ekstansiyon hareketi yapıyor ise BAKS $(1,2,3)$ olarak atanır. 
Tablo 3. Bulanık Tablo B (Fuzzy Table B)

\begin{tabular}{|c|c|c|c|c|c|c|c|}
\hline \multirow{2}{*}{ Bulanık Tablo B } & \multicolumn{7}{|c|}{ BAKS } \\
\hline & & \multicolumn{3}{|c|}{$\tilde{1}$} & \multicolumn{3}{|c|}{$\tilde{2}$} \\
\hline \multirow{7}{*}{ BÜKS } & BBİS & $\tilde{1}$ & $\tilde{2}$ & $\widetilde{3}$ & $\tilde{1}$ & $\tilde{2}$ & $\widetilde{3}$ \\
\hline & $\tilde{1}$ & $\tilde{1}$ & $\tilde{2}$ & $\tilde{2}$ & $\tilde{1}$ & $\tilde{2}$ & $\widetilde{3}$ \\
\hline & $\tilde{2}$ & $\tilde{1}$ & $\tilde{2}$ & $\tilde{3}$ & $\tilde{2}$ & $\tilde{3}$ & 4 \\
\hline & $\widetilde{3}$ & $\tilde{3}$ & $\tilde{4}$ & $\tilde{5}$ & $\tilde{4}$ & $\tilde{5}$ & $\tilde{5}$ \\
\hline & $\tilde{4}$ & $\tilde{4}$ & $\tilde{5}$ & 5 & $\tilde{5}$ & $\tilde{6}$ & $\tilde{7}$ \\
\hline & $\tilde{5}$ & $\tilde{6}$ & $\tilde{7}$ & $\widetilde{8}$ & $\tilde{7}$ & $\widetilde{8}$ & $\widetilde{8}$ \\
\hline & $\tilde{6}$ & $\widetilde{7}$ & $\widetilde{8}$ & $\widetilde{8}$ & $\widetilde{8}$ & $\widetilde{9}$ & 9 \\
\hline
\end{tabular}

Tablo 4. Bulanık Tablo C (Fuzzy Table C)

\begin{tabular}{|c|c|c|c|c|c|c|c|c|c|c|c|c|}
\hline \multirow{3}{*}{ BAS } & \multicolumn{12}{|c|}{ Bulanık Tablo C } \\
\hline & \multicolumn{12}{|c|}{ BBS } \\
\hline & $\widetilde{\mathbf{1}}$ & $\widetilde{2}$ & $\widetilde{3}$ & $\widetilde{4}$ & $\widetilde{\mathbf{5}}$ & $\widetilde{6}$ & $\widetilde{7}$ & $\widetilde{8}$ & $\widetilde{9}$ & $\widetilde{\mathbf{1 0}}$ & $\widetilde{\mathbf{1 1}}$ & $\widetilde{12}$ \\
\hline$\widetilde{\mathbf{1}}$ & $\tilde{1}$ & $\tilde{1}$ & $\tilde{1}$ & $\tilde{2}$ & $\widetilde{3}$ & $\widetilde{3}$ & $\tilde{4}$ & $\tilde{5}$ & $\tilde{6}$ & $\tilde{7}$ & $\tilde{7}$ & $\tilde{7}$ \\
\hline$\widetilde{2}$ & $\tilde{1}$ & $\tilde{2}$ & $\tilde{2}$ & $\widetilde{3}$ & $\tilde{4}$ & $\tilde{4}$ & $\tilde{5}$ & $\tilde{6}$ & $\tilde{6}$ & $\tilde{7}$ & $\tilde{7}$ & $\widetilde{8}$ \\
\hline$\widetilde{\mathbf{3}}$ & $\tilde{2}$ & $\tilde{3}$ & $\tilde{3}$ & $\tilde{3}$ & $\tilde{4}$ & $\tilde{5}$ & $\tilde{6}$ & $\tilde{7}$ & $\tilde{7}$ & $\tilde{8}$ & $\tilde{8}$ & $\tilde{8}$ \\
\hline$\widetilde{4}$ & $\widetilde{3}$ & $\tilde{4}$ & $\tilde{4}$ & $\tilde{4}$ & $\tilde{5}$ & $\tilde{6}$ & $\tilde{7}$ & $\widetilde{8}$ & $\widetilde{8}$ & $\tilde{9}$ & $\tilde{9}$ & $\tilde{9}$ \\
\hline$\widetilde{\mathbf{5}}$ & $\tilde{4}$ & $\tilde{4}$ & $\tilde{4}$ & $\tilde{5}$ & $\tilde{6}$ & $\tilde{7}$ & $\tilde{8}$ & $\tilde{8}$ & $\tilde{9}$ & $\tilde{9}$ & $\widetilde{9}$ & $\tilde{9}$ \\
\hline$\widetilde{6}$ & $\tilde{6}$ & $\tilde{6}$ & $\tilde{6}$ & $\tilde{7}$ & $\tilde{8}$ & $\tilde{8}$ & $\tilde{9}$ & $\widetilde{9}$ & $\widetilde{10}$ & $\widetilde{10}$ & $\widetilde{10}$ & $\widetilde{10}$ \\
\hline$\widetilde{7}$ & $\tilde{7}$ & $\tilde{7}$ & $\tilde{7}$ & $\tilde{8}$ & $\tilde{9}$ & $\widetilde{9}$ & $\widetilde{9}$ & $\widetilde{10}$ & $\widetilde{10}$ & $\widetilde{11}$ & $\widetilde{11}$ & $\widetilde{11}$ \\
\hline$\widetilde{\mathbf{8}}$ & $\tilde{8}$ & $\widetilde{8}$ & $\tilde{8}$ & $\widetilde{9}$ & $\widetilde{10}$ & $\widetilde{10}$ & $\widetilde{10}$ & $\widetilde{10}$ & $\widetilde{10}$ & $\widetilde{11}$ & $\widetilde{11}$ & $\widetilde{11}$ \\
\hline$\widetilde{\mathbf{9}}$ & $\widetilde{9}$ & $\tilde{9}$ & $\widetilde{9}$ & $\widetilde{10}$ & $\widetilde{10}$ & $\widetilde{10}$ & $\widetilde{11}$ & $\widetilde{11}$ & $\widetilde{11}$ & $\widetilde{12}$ & $\widetilde{12}$ & $\widetilde{12}$ \\
\hline$\widetilde{\mathbf{1 0}}$ & $\widetilde{10}$ & $\widetilde{10}$ & $\widetilde{10}$ & $\widetilde{11}$ & $\widetilde{11}$ & $\widetilde{11}$ & $\widetilde{11}$ & $\widetilde{12}$ & $\widetilde{12}$ & $\widetilde{12}$ & $\widetilde{12}$ & $\widetilde{12}$ \\
\hline$\widetilde{\mathbf{1 1}}$ & $\widetilde{11}$ & $\widetilde{11}$ & $\widetilde{11}$ & $\widetilde{11}$ & $\widetilde{12}$ & $\widetilde{12}$ & $\widetilde{12}$ & $\widetilde{12}$ & $\widetilde{12}$ & $\widetilde{12}$ & $\widetilde{12}$ & $\widetilde{12}$ \\
\hline$\widetilde{12}$ & $\widetilde{12}$ & $\widetilde{12}$ & $\widetilde{12}$ & $\widetilde{12}$ & $\widetilde{12}$ & $\widetilde{12}$ & $\widetilde{12}$ & $\widetilde{12}$ & $\widetilde{12}$ & $\widetilde{12}$ & $\widetilde{12}$ & $\widetilde{12}$ \\
\hline
\end{tabular}

Tablo 5. BREBAFS Tablosu (Fuzzy REBA Final Scores (FREBAFS) Table)

\begin{tabular}{|c|c|c|}
\hline BS & ÜBS & Eylem Seviyesi \\
\hline$\tilde{1}$ & $(1,1,2)$ & Önemsiz bir risk \\
\hline$\widetilde{2}$ veya $\widetilde{3}$ & $(1,2,3)$ veya $(2,3,4)$ & Düşük risk, değişiklik gerekebilir \\
\hline$\tilde{4}$ 'den $\tilde{7}$ 'ye kadar & $\begin{array}{l}(3,4,5) \text { 'den }(6,7,8) \text { 'e } \\
\text { kadar }\end{array}$ & $\begin{array}{c}\text { Orta düzeyde risk, daha fazla araştırma gerekli, } \\
\text { değişiklikler kısa zamanda yapılmalı }\end{array}$ \\
\hline $\begin{array}{l}\text { 8’den } \widetilde{10}{ }^{\prime} a \\
\text { kadar }\end{array}$ & $\begin{array}{c}(7,8,9) \text { 'den } \\
(9,10,11) \text { 'e kadar }\end{array}$ & $\begin{array}{c}\text { Yüksek risk, araştırma yapılarak değişiklikler en kısa } \\
\text { zamanda uygulanmalı }\end{array}$ \\
\hline$\widetilde{11}+$ & $(10,11,12)$ & Çok yüksek risk, değișiklikler hemen uygulanmalı \\
\hline
\end{tabular}

Adım 9: Bu adım bilek bölümüne ait dört farklı açısal duruşun ve bir adet opsiyonel hareketin değerlendirilmesinden oluşur. Bilek $15^{\circ}$ ekstansiyon veya fileksiyon hareketini yapıyor ise $(1,1,2), 15^{\circ}$ 'den fazla fileksiyon veya ekstansiyon hareketini yapıyor ise $(1,2,3)$ ÜBS'ları atanır. İki farklı opsiyonel hareket (orta bölgeden bükülmüşse veya dönmüşse $(+1)$ ) ise net bir şekilde belirlenebildiği için bu hareketlere ait puanlar kesin değer olarak alınmıştır. Bu değerler ÜBS'lara eklenerek Bulanık Bilek Skoru (BBİS) elde edilir.

Adım 10: 7, 8 ve 9. adımlarda hesaplanan BS'lar Tablo 3 ile verilen Bulanık Tablo B'de kesiştirilerek B Grubuna ait BS elde edilir. Buna göre öncelikle BAKS, sonra BBİS belirlenir ve BÜKS ile BBİS kesiştirilerek B Grubuna ait BS bulunur.
Adım 11: $\mathrm{Bu}$ adımda, yükü kavrama kalitesinin belirlendiği dört farklı kavrama koşulu değerlendirilir. Bunlar net bir şekilde belirlenebildiği için koşullara ait puanlar kesin değer olarak verilmiştir.

Buna göre kabul edilebilir ancak ideal olmayan veya diğer bir vücut bölümünün desteğiyle kavrama yapilabiliyorsa Kavrama Skoru (KAS) (+1) olarak alınır. Zorlanarak yapılan kabul edilemez bir kavrama mevcutsa $(+2)$ ve herhangi bir tutamaç olmadan, güvensiz bir kavrama yapılıyorsa $(+3)$ kesin sayıları atanır.

Adım 12: KAS, B Grubuna ait BS'a eklenerek Bulanık B Skoru (BBS) elde edilir. Ayrıca BAS ile BBS Tablo 4 ile verilen Bulanık Tablo C'de kesiştirilerek Bulanık C Skoru (BCS) bulunur. 
Adım 13: $\mathrm{Bu}$ adımda aktivite skoru belirlenerek sergilenen duruşun statik olup olmadı̆̆ $(1 \mathrm{dk}$.'dan fazla aynı hareket yapılıyorsa $(+1), 1$ dk.'da 4 defadan fazla küçük mesafelerle tekrarlı hareket yapılıyorsa (+1), duruşlarda hızlı, büyük mesafeli değişimler yaşanıyorsa veya dengesiz bir zeminde duruş sergileniyorsa $(+1)$ ) değerlendirilir. Değerlendirme net olarak yapılabildiği için skorlar kesin değer olarak alınmıştır.

Adım 14: Aktivite skoru ile BCS toplanarak Tablo 5 ile verilen Bulanık REBA Final Skoru (BREBAFS) elde edilir.

\section{UYGULAMA VE BULGULAR (APPLICATION AND RESULTS)}

Geliştirilen BREBA algoritması firmanın pim imalat sürecinde sergilenen çalışma duruşlarının analizinde kullanılmıştır. Pim imalat sürecinde çalışanların kendi istedikleri zamanlarda işlenmiş veya işlenmekte olan pimleri soğuma alanlarına ve nihai mamul stok alanına taşıdıkları gözlemlenmiştir. Ayrıca, pim imalatında kullanılan çelik hammaddenin belirsiz periyotlarda kesilmesi işlemi de, sıkça hammaddenin imalat alanına taşınmasına sebep olmaktadır. Bu tür düzensiz taşıma ve kesme faaliyetleri, süreçte yaşanan tekrarlı hareketlerden ve rahatsızlık veren çalışma duruşlarından kaynaklanmaktadır. Çalışanlar, bu faaliyetleri gerçekleştirirken pozisyon değiştirmekte ve oluşan kas yorgunluğunu azaltmaya çalışmaktadırlar. Ancak bu faaliyetler de manuel yapıldığı için yine yorgunluk ve ağrı gibi olumsuz etkiler yaratmaktadir. $\mathrm{Bu}$ problemler, imalat alanındaki iş istasyonlarının ergonomik açıdan uygun bir tasarıma sahip olmamasından kaynaklanmaktadır. $\mathrm{Bu}$ durum, başlangıçta bir pimin imalatı için gerekli olan üretim süresini etkilemese de zaman ilerledikçe çalışanda oluşan yorgunluk nedeniyle bu süre artmaktadır. Verim düşüklüğünü önleyebilmek için iş istasyonu tasarımlarının yapılan işe ve çalışana uygun hale getirilmesi gerekmektedir.

Pim imalat süreci, ısıl işlem istasyonu (indüksiyon ocağ1), birinci pres istasyonu, ikinci pres istasyonu ve taşıma istasyonu olmak üzere dört farklı istasyona ayrılmıştır. $\mathrm{Bu}$ istasyonlarda sergilenen çalışma duruşları fotoğraflama yöntemi ile toplanmıştır. Bu kapsamda 688 adet duruş fotoğrafi elde edilerek BREBA Yöntemi ile analiz edilmiştir.

Tablo 6 ve 7'de istasyonlara göre sergilenen çalışma duruşlarının sırasıyla A ve B gruplarında yer alan vücut bölümlerine ait bulanık skor sıklıları yer almaktadır.

Tablo 6 ve Tablo 7'de verilen BS'lar belirlenirken en yüksek sıklığa sahip değerler dikkate alınmıştır. Tablo 6'ya göre isıl işlem istasyonunda BBOS açısından en yüksek sıklığa sahip BS 122 adetle "テ̃ " olarak elde edilmiştir. Buna göre boyun duruşları için risk seviyesi önemsizdir. Aynı istasyonda BGS açısından en yüksek sıklığa sahip BS'un 205 adetle " $\widetilde{2}$ " olduğu görülmüştür. $\mathrm{Bu}$ duruş, gövdenin $0^{\circ}-20^{\circ}$ aras1 fileksiyonda olduğunu gösterir. Buradan gövde duruşlarının boyun duruşlarına göre daha fazla risk içerdiği belirlenmiştir. BBAS incelendiğinde en

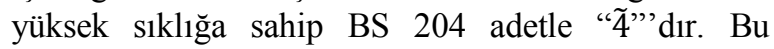
sonuçlar, A grubundaki vücut bölümleri açısından isıl işlem istasyonunda en çok bacakların zorlandığını göstermektedir. Birinci ve ikinci pres istasyonları incelendiğinde ise boyun ve gövde duruşlarının eşit derecede riske sahip olduğu ancak bacak duruşlarının bu bölümlere göre daha fazla risk içerdiği görülmektedir. Taşıma istasyonunda en riskli duruşa sahip olan bölüm gövde olarak elde edilmiş, boyun

Tablo 6. İş İstasyonlarında Sergilenen Çalışma Duruşlarının A Grubu BS Sıklıkları (Group A Fuzzy Scores Frequencies of Working Postures Exhibited in Work Stations)

\begin{tabular}{|c|c|c|c|c|c|c|c|c|c|c|c|}
\hline \multicolumn{12}{|c|}{ A Grubu } \\
\hline \multirow{2}{*}{ İstasyonlar } & \multicolumn{3}{|c|}{$\overline{\mathrm{BBOS}}$} & \multicolumn{4}{|c|}{ BGS } & \multicolumn{4}{|c|}{ BBAS } \\
\hline & $\tilde{1}$ & $\tilde{2}$ & $\tilde{3}$ & $\tilde{2}$ & $\tilde{3}$ & $\tilde{4}$ & $\tilde{5}$ & $\tilde{1}$ & $\tilde{2}$ & $\tilde{3}$ & $\tilde{4}$ \\
\hline Isıl İşlem İstasyonu & $122^{*}$ & 71 & 12 & $205^{*}$ & 0 & 0 & 0 & 1 & 0 & 0 & $204^{*}$ \\
\hline Birinci Pres İstasyonu & 101 & $128 *$ & 78 & $146^{*}$ & $115^{*}$ & 36 & 10 & 0 & 3 & 0 & $304 *$ \\
\hline İkinci Pres İstasyonu & 19 & 31 & $47 *$ & 26 & $50 *$ & 13 & 8 & 1 & 0 & 0 & $96 *$ \\
\hline Taşıma İstasyonu & 6 & $48^{*}$ & 25 & 11 & $47 *$ & 11 & 10 & $43 *$ & 0 & 19 & 17 \\
\hline
\end{tabular}

*İstasyonlara göre en yüksek sıklığa sahip BBOS, BGS ve BBAS değerleri.

Tablo 7. İş İstasyonlarında Sergilenen Çalışma Duruşlarının B Grubu BS Sıklıkları (Group B Fuzzy Scores Frequencies of Working Postures Exhibited in Work Stations)

\begin{tabular}{|l|c|c|c|c|c|c|c|c|c|c|c|}
\hline \multicolumn{10}{|c|}{ B Grubu } \\
\hline \multirow{2}{*}{ İstasyonlar } & \multicolumn{9}{|c|}{ BÜS } & \multicolumn{1}{c|}{ BAKS } & \multicolumn{3}{c|}{ BBİS } \\
\cline { 2 - 14 } & $\tilde{1}$ & $\tilde{2}$ & $\tilde{3}$ & $\tilde{4}$ & $\tilde{5}$ & $\tilde{6}$ & $\tilde{1}$ & $\tilde{2}$ & $\tilde{1}$ & $\tilde{2}$ & $\tilde{3}$ \\
\hline Isıl İşlem İstasyonu & 7 & $125^{*}$ & 72 & 1 & 0 & 0 & $189^{*}$ & 16 & 54 & $123^{*}$ & 28 \\
\hline Birinci Pres İstasyonu & $207^{*}$ & 24 & 57 & 9 & 0 & 0 & $232^{*}$ & 75 & 21 & $284^{*}$ & 2 \\
\hline İkinci Pres İstasyonu & $48^{*}$ & 27 & 15 & 2 & 3 & 2 & $71^{*}$ & 26 & 7 & $59^{*}$ & 31 \\
\hline Taşıma İstasyonu & 14 & 16 & $28^{*}$ & 15 & 4 & 2 & $58^{*}$ & 21 & 5 & $61^{*}$ & 13 \\
\hline
\end{tabular}

*İstasyonlara göre en yüksek sıklığa sahip BÜKS, BAKS ve BBİS değerleri. 
Tablo 8. Bulanık Tablo A Skoru, BYKS, BAS'larına ait S1klıklar (Frequencies of Fuzzy Table A Scores, Fuzzy Load Force Scores (FLFS) and Fuzzy A Scores (FAS))

\begin{tabular}{|l|c|c|c|c|c|c|c|c|c|c|c|c|c|c|c|c|c|c|c|}
\hline \multirow{2}{*}{ İstasyonlar } & \multicolumn{1}{|c|}{ Bulanı Tablo A Skoru } & \multicolumn{1}{|c|}{ BYKS } & \multicolumn{1}{|c|}{ BAS } \\
\hline $\begin{array}{l}\text { Isıl İşlem } \\
\text { İstasyonu }\end{array}$ & 0 & 1 & 0 & 121 & 71 & 12 & 0 & 0 & 205 & 0 & 0 & 1 & 0 & 121 & 71 & 12 & 0 & 0 & 0 \\
\hline $\begin{array}{l}\text { Birinci } \\
\text { Pres } \\
\text { İstasyonu }\end{array}$ & 0 & 0 & 1 & 67 & 83 & 82 & 55 & 19 & 307 & 0 & 0 & 0 & 1 & 67 & 83 & 82 & 55 & 19 & 0 \\
\hline $\begin{array}{l}\text { İkinci Pres } \\
\text { İstasyonu }\end{array}$ & 1 & 2 & 0 & 13 & 10 & 27 & 29 & 15 & 94 & 2 & 1 & 1 & 1 & 14 & 10 & 27 & 29 & 15 & 0 \\
\hline $\begin{array}{l}\text { Taşıma } \\
\text { İstasyonu }\end{array}$ & 1 & 5 & 23 & 17 & 12 & 6 & 5 & 10 & 47 & 30 & 2 & 3 & 14 & 27 & 7 & 7 & 10 & 9 & 2 \\
\hline
\end{tabular}

Tablo 9. Bulanık Tablo B Skoru, KAS, BBS'larına ait Sıklıklar (Frequencies of Fuzzy Table B Scores, Coupling Scores (CS) and Fuzzy B Scores (FBS))

\begin{tabular}{|c|c|c|c|c|c|c|c|c|c|c|c|c|c|c|c|c|c|c|c|c|c|c|c|c|}
\hline \multirow[b]{2}{*}{ İstasyonlar } & \multicolumn{9}{|c|}{ Bulanık Tablo B Skoru } & \multicolumn{4}{|c|}{ KAS } & \multicolumn{11}{|c|}{ BBS } \\
\hline & $\tilde{1} \tilde{1}$ & $\tilde{2}$ & $\tilde{3}$ & $\tilde{4}$ & $\tilde{5}$ & $\tilde{6}$ & $\tilde{7}$ & $\tilde{8}$ & $\tilde{9}$ & 0 & 1 & 2 & 3 & $\tilde{1}$ & $\tilde{2}$ & $\tilde{3}$ & $\tilde{4}$ & $\tilde{5}$ & $\widetilde{6}$ & $\tilde{7}$ & $\widetilde{8}$ & $\widetilde{9}$ & $\widetilde{10}$ & $\widetilde{11}$ \\
\hline $\begin{array}{l}\text { Isıl İşlem } \\
\text { İstasyonu }\end{array}$ & 23 & 77 & 57 & 46 & 2 & 0 & 0 & 0 & 0 & 180 & 1 & 24 & 0 & 17 & 64 & 61 & 55 & 5 & 3 & 0 & 0 & 0 & 0 & 0 \\
\hline $\begin{array}{l}\text { Birinci } \\
\text { Pres } \\
\text { İstasyonu }\end{array}$ & 20 & 199 & 21 & 26 & 36 & 5 & 0 & 0 & 0 & 307 & 0 & 0 & 0 & 20 & 199 & 21 & 26 & 36 & 5 & 0 & 0 & 0 & 0 & 0 \\
\hline $\begin{array}{l}\text { İkinci Pres } \\
\text { İstasyonu }\end{array}$ & 4 & 51 & 19 & 8 & 8 & 2 & 3 & 2 & 0 & 91 & 2 & 1 & 3 & 4 & 50 & 17 & 10 & 9 & 2 & 2 & 0 & 1 & 0 & 2 \\
\hline $\begin{array}{l}\text { Taşıma } \\
\text { İstasyonu }\end{array}$ & 2 & 22 & 7 & 20 & 17 & 4 & 2 & 4 & 1 & 7 & 71 & 1 & 0 & 1 & 3 & 21 & 7 & 20 & 15 & 6 & 1 & 4 & 1 & 0 \\
\hline
\end{tabular}

duruşlarının gövde duruşlarına göre daha az risk taşıdığı, bacak duruşlarının ise gövde ve boyun duruşlarına göre daha önemsiz bir risk seviyesine sahip olduğu belirlenmiştir. Tablo 6 bütün olarak incelendiğinde ise en riskli duruşun ikinci pres istasyonunda sergilenen bacak duruşları olduğu söylenebilir.

B grubu için Tablo 7'de yer alan sonuçlar incelendiğinde 1 sıl işlem istasyonunda üst kol ve bilek duruşlarının eşit derecede riskli, alt kol duruşlarının ise bu duruşlara göre daha önemsiz bir risk seviyesine sahip olduğu gözlenmiştir. Birinci ve ikinci pres istasyonlarında üst kol ve alt kol duruşlarında önemli bir riske rastlanmamış, bilek duruşlarının bunlara oranla daha fazla risk taşıdığı görülmüștür. Taşıma istasyonu açısından alt kol duruşlarının risk içermediği, bilek duruşlarının alt kola göre daha riskli olduğu ve en yüksek riske sahip olan duruşların üst kolda sergilendiği görülmektedir. Bulanık A grubu skorlarının belirlenmesinden sonra Tablo 2 ile verilen
Bulanık Tablo A kullanılarak, Bulanık Tablo A Skoru hesaplanır. Buna göre Bulanık Tablo A Skoru, BYKS ve BAS'larına ait sıklıklar Tablo 8 ile verilmiştir.

Bulanık B grubu skorlarının belirlenmesinden sonra Tablo 3 ile verilen Bulanık Tablo B kullanılarak, Bulanık Tablo B Skoru hesaplanır. Buna göre Bulanık Tablo B Skoru, KAS ve BBS'larına ait sıklıklar Tablo 9 ile verilmiştir. Tablo 4 kullanılarak elde edilen Bulanık Tablo $\mathrm{C}$ ve aktivite skorlarına ilişkin sıklıklar Tablo 10'da verilmiştir.

Pim imalat alanında analiz edilen çalışma duruşlarına ilişkin birkaç örnek Tablo 11 ile verilmiştir. Tablo 11 ile verilen duruş örneklerine ait değerlendirmeler, Kesim 2.2 de verilen BREBA algoritması izlenerek her bir adım için Tablo 12 ile sunulmuştur. Tablo 12 de verilen örnek değerlendirme doğrultusunda 688 adet çalışma duruşu benzer şekilde incelenmiş ve tüm istasyonlara ait BREBAFS'larının sıklıkları Tablo 13'de verilmiştir.

Tablo 10. Bulanık Tablo C Skoru ve Aktivite Skorlarına ait Sıklıklar (Frequencies of Fuzzy Table C Scores, Activity Scores)

\begin{tabular}{|c|c|c|c|c|c|c|c|c|c|c|c|c|}
\hline \multirow{2}{*}{ İstasyonlar } & \multicolumn{10}{|c|}{ Bulanık Tablo C Skoru } & \multicolumn{2}{|c|}{$\begin{array}{c}\text { Aktivite } \\
\text { Skoru }\end{array}$} \\
\hline & $\tilde{2}$ & $\tilde{3}$ & $\tilde{4}$ & $\tilde{5}$ & $\tilde{6}$ & $\tilde{7}$ & $\tilde{8}$ & $\tilde{9}$ & $\widetilde{10}$ & $\widetilde{11}$ & 0 & 1 \\
\hline Isıl İşlem İstasyonu & 0 & 1 & 85 & 31 & 51 & 32 & 5 & 0 & 0 & 0 & 1 & 204 \\
\hline $\begin{array}{l}\text { Birinci Pres } \\
\text { İstasyonu }\end{array}$ & 0 & 0 & 65 & 1 & 74 & 64 & 48 & 32 & 23 & 0 & 0 & 307 \\
\hline İkinci Pres İstasyonu & 0 & 0 & 11 & 0 & 9 & 23 & 26 & 21 & 6 & 1 & 1 & 96 \\
\hline Tașıma İstasyonu & 1 & 2 & 11 & 4 & 13 & 13 & 8 & 13 & 11 & 3 & 0 & 79 \\
\hline
\end{tabular}


Tablo 11. İș İstasyonlarında Sergilenen Örnek Çalışma Duruşları (Working Postures Represented in Work Stations)

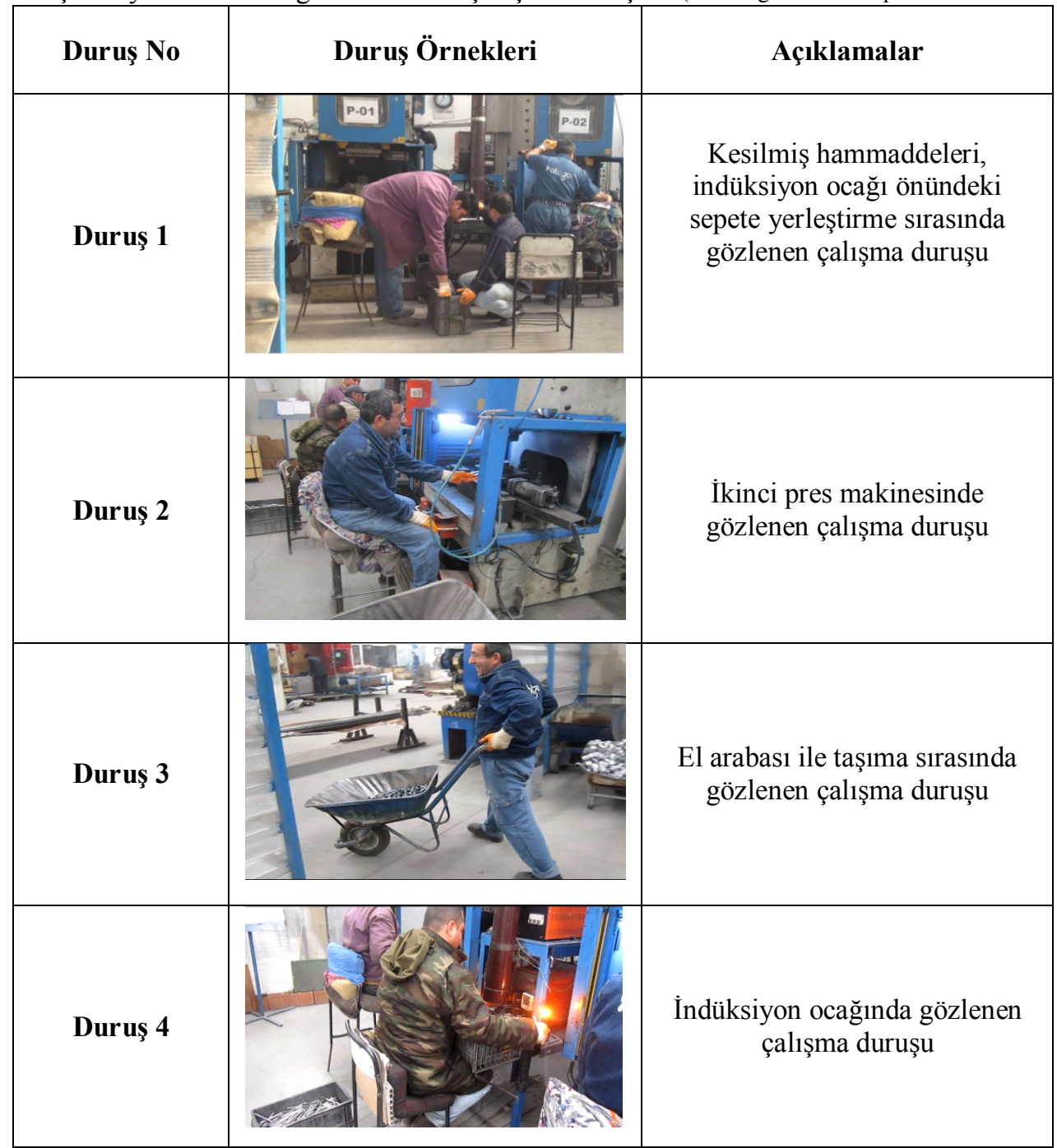

Tablo 12. Örnek Çalışma Duruşlarının BREBA ile Analizi (Analysing Sample Working Postures with BREBA)

\begin{tabular}{|c|c|c|c|c|c|c|c|c|c|}
\hline $\begin{array}{c}\text { Duruş } \\
\text { No }\end{array}$ & $\begin{array}{c}\text { Grup A } \\
\text { BS }\end{array}$ & BYKS & BAS & $\begin{array}{c}\text { Grup } \\
\text { B } \\
\text { BS }\end{array}$ & KAS & BBS & BCS & $\begin{array}{c}\text { Aktivite } \\
\text { Skoru }\end{array}$ & BREBAFS \\
\hline 1 & $\tilde{5}$ & 0 & $\tilde{4}$ & $\tilde{3}$ & 0 & $\tilde{3}$ & $\tilde{4}$ & 1 & $\tilde{5}$ \\
\hline 2 & $\tilde{4}$ & 0 & $\tilde{5}$ & $\tilde{1}$ & 0 & $\tilde{1}$ & $\tilde{4}$ & 1 & $\tilde{5}$ \\
\hline 3 & $\tilde{3}$ & 1 & $\tilde{4}$ & $\tilde{5}$ & 0 & $\tilde{5}$ & $\tilde{5}$ & 1 & $\tilde{6}$ \\
\hline 4 & $\tilde{7}$ & 0 & $\tilde{7}$ & $\tilde{5}$ & 0 & $\tilde{5}$ & $\tilde{9}$ & 1 & $\tilde{10}$ \\
\hline
\end{tabular}

Tablo 13. BREBAFS'larının İstasyonlara Göre S1klıkları (Frequencies of FREBAFS According to Work Stations)

\begin{tabular}{|c|c|c|c|c|c|c|c|c|c|c|}
\hline \multirow{2}{*}{ İstasyonlar } & \multicolumn{10}{|c|}{ BREBAFS } \\
\hline & $\tilde{3}$ & $\tilde{4}$ & $\tilde{5}$ & $\tilde{6}$ & $\tilde{7}$ & $\tilde{8}$ & $\widetilde{9}$ & $\widetilde{10}$ & $\widetilde{11}$ & $\widetilde{12}$ \\
\hline Isıl İşlem İstasyonu & 0 & 2 & $84 *$ & 31 & 51 & 32 & 5 & 0 & 0 & 0 \\
\hline Birinci Pres İstasyonu & 0 & 20 & $65^{*}$ & 1 & 74 & 64 & 48 & 32 & 23 & 0 \\
\hline İkinci Pres İstasyonu & 0 & 0 & 11 & 0 & 9 & 24 & $25 *$ & 21 & 6 & 1 \\
\hline Taşıma İstasyonu & 1 & 2 & 11 & 4 & $13 *$ & $13 *$ & 8 & $13 *$ & 11 & 3 \\
\hline
\end{tabular}

*İstasyonlara göre en yüksek sıklığa sahip BREBAFS.

Tablo 13'e göre 1sil işlem ve birinci pres istasyonlarında sergilenen duruşlar Tablo 5 ile verilen BREBAFS Tablosu kapsamında orta düzeyde risk içermektedir. Bu riski önlemek için yapılması gereken değişimlerin kısa zamanda uygulanması gerekmektedir. Bununla birlikte ikinci pres istasyonunda sergilenen duruşlar yüksek düzeyde risk içermekte ve bu riskin önlenmesi için değişimlerin en 
Tablo 14. BREBAFS Siklık Tablosu (FREBAFS Frequency Table)

\begin{tabular}{|c|c|c|c|}
\hline $\begin{array}{l}\text { Bulanık } \\
\text { Skorlar }\end{array}$ & ÜBS & Eylem Seviyesi & $\begin{array}{c}\text { Siklik } \\
(\mathrm{n}=688)\end{array}$ \\
\hline$\tilde{1}$ & $(1,1,2)$ & Önemsiz bir risk & - \\
\hline$\widetilde{2}$ veya $\widetilde{3}$ & $\begin{array}{l}(1,2,3) \text { veya } \\
(2,3,4)\end{array}$ & Düşük risk, değişiklik gerekebilir & 1 \\
\hline $\begin{array}{l}\tilde{4}^{\prime} \text { 'den } \tilde{7} \text { 'ye } \\
\text { kadar }\end{array}$ & $\begin{array}{c}(3,4,5) \text { 'den } \\
(6,7,8) \text { 'e } \\
\text { kadar }\end{array}$ & $\begin{array}{l}\text { Orta düzeyde risk, daha fazla araştırma gerekli, değişiklikler } \\
\text { kısa zamanda yapılmalı }\end{array}$ & $358 *$ \\
\hline $\begin{array}{l}\text { 8'den } \widetilde{10} \text { 'a } \\
\text { kadar }\end{array}$ & $\begin{array}{c}(7,8,9) \text { 'den } \\
(9,10,11)^{\prime} \text { 'a } \\
\text { kadar }\end{array}$ & $\begin{array}{c}\text { Yüksek risk, araştırma yapılarak değişiklikler en kısa zamanda } \\
\text { uygulanmalı }\end{array}$ & 219 \\
\hline$\widetilde{11}+$ & $(10,11,12)$ & Çok yüksek risk, değişiklikler hemen uygulanmalı & 110 \\
\hline
\end{tabular}

*Pim imalat sürecinde en yüksek sıklığa sahip eylem seviyesi.

kısa zamanda uygulanması önerilmektedir. Taşıma istasyonunda ise en fazla $\tilde{7}, \tilde{8}$ ve $\widetilde{10}$ skorları ortaya çıkmıştır. Bu durum bulanık mantığın klasik mantığa kattığı değerlendirme esnekliğini gösterir. $\mathrm{Bu}$ istasyonda sergilenen duruşların daha çok yüksek derecede risk taşıdığı söylenebilir. Buna göre bu istasyon için tasarım iyileştirmelerinin hemen uygulanması gerekmektedir.

Pim imalat süreci, sergilenen çalışma duruşları açısından bir bütün olarak ele alındığında Tablo 14'de verilen BREBAFS Sıklık Tablosu elde edilmektedir. Tablo 14'e göre pim imalat sürecinde sergilenen duruşlar, çalışan sağlığı ve imalat süreci açısından orta düzeyde risk oluşturmaktadır.

\section{SONUÇ ve ÖNERILER (RESULTS AND RECOMENDATIONS)}

Çalışmada önerilen BREBA Yönteminin açısal duruş değerlendirmelerinde, gözlemler açısından, klasik yönteme göre daha esnek bir yapıya sahip olduğu görülmüştür. Bu durum çalışma hayatına daha uygun sonuçların elde edilmesine olanak sağlamıştır.

Tablo 12'de verilen BREBAFS'na bakıldığında $\% 52,03$ ile sergilenen duruşların orta düzeyde risk içerdiği görülmektedir. Bunu \%31,83 ile yüksek risk ve \% 15,99 ile çok yüksek risk seviyeleri takip etmektedir. Düşük risk seviyesi ise $\% 0,15$ ile çok az bir orana sahiptir. Önemsiz risk seviyesi ise \% 0 olarak bulunmuştur. Buna göre çalışma duruşlarının yarısının orta düzeyde risk içerdiği belirlenmiştir. Aynı zamanda yüksek düzeyde risk içeren duruşların oranı da yadsınamayacak kadar fazladır. Sonuç olarak pim imalatındaki iş istasyonu tasarımlarının bu duruşları azaltacak şekilde iyileştirilmesi gerekmektedir.

Sonuçlar, 1sıl işlem istasyonunun mevcut tasarımında en çok zorlanan vücut bölümünün bacaklar olduğunu göstermektedir. Buna göre istasyonda, bacak bölümünü rahatlatmak için bir ayak desteğinin bulunması gereklidir. Ayak desteğinin seçiminde, çalışanın konforu açısından ayarlanabilir olmasına ve yüzey genişliğine dikkat edilmelidir. Aynı istasyon için bacaklardan sonra en fazla zorlanan bölümler üst kol, bilek ve gövdedir. Bu nedenle üst kol ve bilek rahatlığ 1 için farklı kol desteği alternatifleri ve gövde için de farklı oturma düzenekleri belirlenmelidir. Seçilen kol destekleri indüksiyon ocağına monte edilebilecek portatif destekler olmalıdır. Çünkü çalışanlar sürekli dirseklerini ocağa dayayarak görevlerini yapmaktadırlar. Oturma düzeneği alternatifleri seçilirken ise ayarlanabilir sırt desteği olmasına ve döşeme tipine dikkat edilmelidir. Çünkü çalışan, ayarlanabilir sırt desteği yardımıyla yaptığı işe uygun bir gövde açısında durabilecektir. Döşeme tipi ise mevcut durumda sicak olan üretim ortamında terlemeyi önleyecek biçimde seçilmelidir.

Ayrıca, her iki pres istasyonunda bacak ve gövde bölümlerini rahatlatıcı tasarım iyileştirmelerinin yapılması gerektiği anlaşılmaktadır. Hem bacak hem gövde konforunun bir arada sağlanması uygun oturma düzenekleri ile mümkündür. Pres işlemi, pedallara basılarak yapıldığı için bu istasyonlarda ayak desteği bulunması gerekmemektedir. Çalışanın pedalı kullanmadığı zamanlarda oturma düzeneğinde bulunan ayak desteğinden yararlanması uygun olacaktır. Oturma düzeneği alternatifleri seçilirken ayarlanabilir kol desteğinin, boyun desteğinin, ayarlanabilir sırt desteğinin olması, uygun döşeme tipi ve ayak desteğinin şekli gibi hususlara dikkat edilmelidir. Çünkü pres işleminde çalışan, kollarını dayayabileceği bir yere ve pedal kullanmadığı ayağını koyabileceği bir desteğe ihtiyaç duymaktadır.

Manuel olarak işlemlerin yapıldığı taşıma istasyonunda ise üst kol ve gövde bölümlerinin rahatlatılması için farklı taşıma sistemleri dikkate alınmalıdır. Bu taşıma sistemlerinin eğimli, yüksekliği ayarlanabilir ve tekerlekli olması tercih edilmelidir. Bunun nedeni mevcut durumda el arabaları ile taşıma yapılması ve çalışanın bu arabayı ilerletmek için fazla kuvvet harcayarak zorlanmasıdır. Pim imalat süreci bir bütün olarak incelendiğinde, süreçte sergilenen 
duruşların orta düzeyde risk içerdiği ve bu duruşları azaltacak tasarım iyileştirmelerinin yakın zamanda yapılması gerektiği belirlenmiştir. İstasyonlara özgü önerilen tasarım uygulamaları gerçekleştirildiği takdirde yukarıda bahsedilen risk düzeylerinin önemli düzeyde azalacağı değerlendirilmektedir.

\section{KAYNAKLAR (REFERENCES)}

1. Das, B. ve Sengupta, A.K., "Industrial Workstation Design: A systematic Ergonomics Approach", Applied Ergonomics, Cilt 27, No 3, 157-163, 1996.

2. Erdem, M.A., Ergonomik İş İstasyonu Dizaynı, Yüksek Lisans Tezi, Gazi Üniversitesi, Fen Bilimleri Enstitüsü, 2000.

3. Akay D., Dağdeviren M., Kurt M., "Çalışma Duruşlarının Ergonomik Analizi”, Journal of The Faculty of Engineering and Architecture of Gazi University Cilt 18, No 3, 73-84, 2003.

4. Buchholz, B., Paquet, V., Punnet, L., Lee, D., Moir, S., "PATH: A Work Sampling-based Approach to Ergonomic Job Analysis for Construction and Other Non-repetitive Work", Applied Ergonomics, Cilt 27, No 3, 177-187, 1996.

5. Higgnet, S., Mcatamney, L., "Technical Note, Rapid Entire Body Assessment", Applied Ergonomics, Cilt 31, No 2, 201-205, 2000.

6. Choobineh, A., Tosian R., Alhamdi Z., Davarzanie M.H., "Ergonomic İntervention in Carpet Mending Operation", Applied Ergonomics, Cilt 35, No 5, 493-496, 2004.

7. Shuval K. ve Donchin M., "Prevalence of Upper Extremity Musculoskeletal Symptoms and Ergonomic Risk Factors at a Hi-tech Company in Israel", International Journal of Industrial Ergonomics, Cilt 35, 569-581, 2005.

8. Diniz de SA, F., Do Nascimento M.A., Carvalho De Melo A.C., Da Costa Santos J., Adissi P. J., "Comparision of methods RULA and REBA for evaluation of postural stress in odontological services", Third International Conference on Production Research-Americas' Region 2006 (ICPR-AM06), Brazil, July 30-August 22006.

9. Jones, T. ve Kumar, S., "Comparision of Ergonomic Assessments in a Repetitive HighRisk Sawmill Occupation: Saw Filer", International Journal of Industrial Ergonomics, Cilt 37, 744-753, 2007.

10. Battini, D., Faccio, M., Persona, A., Sgarbossa, F., "New Methodological Framework to Improve Productivity and Ergonomics in Assembly
System Design", International Journal of Industrial Ergonomics, Cilt 41, 30-42, 2011.

11. Kaufman-Cohen, Y.N. ve Ratzon Z., "Correlation Between Risk Factors and Musculoskeletal Disorders Among Classical Musicians", Occupational Medicine, Cilt 61, No 2, 90-95, 2011.

12. Dockrell, S., O’grady, E., Bennett, K., Mularkey, C., Mc Connell, R., Ruddy, R., Twomey, S., Flannery, C., "An Investigation of Reliability of Rapid Upper Limb Assessment (RULA) as a Method of Children's Computing Posture", Applied Ergonomics, Cilt 43, No 3, 632-636, 2012.

13. Liu, N., Wu, L.M., Wang, M., Niu, Y., Zhang, Y., Wang, W.Z., "Ergonomics Evaluation of Mobile Maintenance Shelter with Fuzzy AHP Method", Applied Mechanics and Materials, Cilt 130-134, 2920-2923, 2011.

14. Abargohei, N.S., Nasab-Hosaini, H., Fakhrzad, M.B., "Design of the Evaluation Model for Total Ergonomics Interventions with Fuzzy Approach", Scientific Journal of Pure and Applied Sciences, Cilt 1, No 3, 119-129, 2012.

15. Zhou, D., Cao, Q-Y., Jia, X., Guo, Z-Q, "A Maintenance Working-Posture Evaluation Methodology Based on Shaperecorder", 2013 International Conference on Quality, Reliability, Risk, Maintenance and Safety Engineering (QR2MSE), 1219-1223, 2013.

16. Isa, H., Rahman, M.A., Hazmilah, H., Sihombing, H., Saptari, A., Baharudin, A.B., Syaheera, A., "Ergonomic Design of CNC Milling Machine for Safe Working Posture", Applied Mechanics and Materials, Cilt 465466, 60-64, 2013.

17. Atalay, K.D. ve Eraslan, E., "Multi-Criteria Usability Evaluation of Electronic Devices in a Fuzzy Environment", Human Factors of Ergonomics in Manufacturing and Service Industries, Cilt 24, No 3, 335-347, 2014.

18. Stoeva, S. ve Nikov, A., "A Fuzzy KnowledgeBased Mechanism for Computer-Aided Ergonomic Evaluation of Industrial Products", Modelling, Simulation \& Control, Cilt 25, No 3, 17-29, 1991.

19. Klir, G.J. ve Yuan, B., Fuzzy Sets and Fuzzy Logics, Prentice Hall PTR, 1995.

20. Ross, T.J., Fuzzy Logic with Engineering Applications, John Wiley\&Sons, 2010.

21. Zadeh, L.A., "Fuzzy Sets", Information and Control, Cilt 8, 338-353, 1965. 